\title{
Chaperonin-Inspired pH Protection by Mesoporous Silica SBA-15 on Myoglobin and Lysozyme
}

\author{
Michele M. Lynch, Jichuan Liu, Michael Nigra, and Marc-Olivier Coppens* \\ Department of Chemical Engineering, University College London, London WC1E 7JE, United Kingdom \\ Supporting Information
}

ABSTRACT: While enzymes are valuable tools in many fields of biotechnology, they are fragile and must be protected against denaturing conditions such as unfavorable solution $\mathrm{pH}$. Within living organisms, chaperonins help enzymes fold into their native shape and protect them from damage. Inspired by this natural solution, mesoporous silica SBA-15 with different pore diameters is synthesized as a support material for immobilizing and protecting enzymes. In separate experiments, the model enzymes myoglobin and lysozyme are physically adsorbed to SBA-15 and exposed to a range of buffered $\mathrm{pH}$ conditions. The immobilized enzymes' biocatalytic activities are quantified and compared to the activities of nonimmobilized enzymes in the same solution conditions. It has been observed that myoglobin immobilized on SBA-15 is protected from acidic denaturation from $\mathrm{pH} 3.6$ to 5.1, exhibiting relative activity of up to $350 \%$. Immobilized lysozyme is protected from unfavorable conditions from $\mathrm{pH} 6.6$ to 7.6 , with relative activity of up to $200 \%$. These results indicate that the protective effects conferred to enzymes immobilized by physical adsorption to SBA-15 are driven by the enzymes' electrostatic attraction to the material's surface. The pore diameter of SBA-15 affects the quality of protection given to immobilized enzymes, but the contribution of this effect at different $\mathrm{pH}$ values remains unclear.
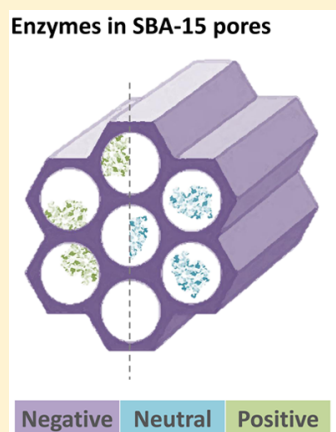

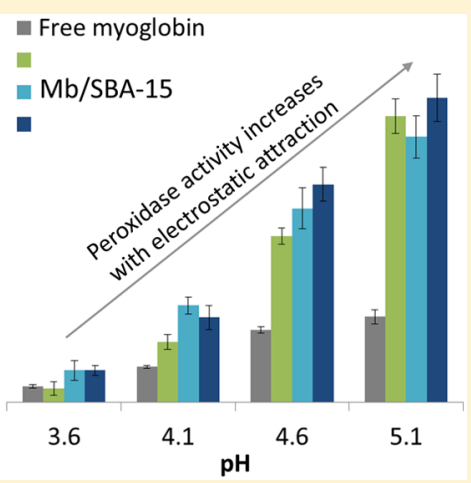

\section{INTRODUCTION}

Nature's Catalysts. Making chemical reactions fast, specific, and efficient has always been a top priority for chemical engineers. Living organisms are able to do this intrinsically through the use of enzymes, which ensure that bioorganic reactions proceed quickly to the correct products. Enzymes can increase rates of reaction by between $10^{6}$ and $10^{12}$ times the rate of the uncatalyzed reaction, and often several orders of magnitude greater than corresponding synthetic catalysts. Biocatalysis makes use of enzymes, either in a purified form or within cells, and is used extensively in the manufacturing of fine chemicals ${ }^{1-3}$ and in the synthesis of chiral pharmaceutical intermediates. ${ }^{4-7}$

Biocatalysis provides not only high selectivity, but also mild reaction conditions which decrease the incidence of epimerization, isomerization, racemization, and rearrangement. Biocatalysis takes place between ambient and biological temperatures, reducing the energy needed for heating and cooling processes. Organic solvents are used less frequently, which reduces waste production. Biotransformations also avoid the necessity of protecting functional groups, which reduces the raw materials required and increases yield. Regardless of industry, biocatalysis is central to sustainable chemistry. ${ }^{8-10}$

Enzymes have evolved to operate optimally within their host organisms in a neutral, aqueous solution at moderate temperature. However, these reaction conditions are incompatible with most industrial processes, and exposure to extreme conditions will result in the enzyme's denaturation. Several conditions lead to denaturation. In order of importance, these are temperature, $\mathrm{pH}$, detergents, and chaotropic agents.

Enzyme immobilization is the most widely used solution to the problem of enzyme fragility. Attaching enzymes to an inert, insoluble material can increase their operational stability. Immobilization has the additional, significant benefit of allowing the enzyme to be easily removed and recycled. There are many methods of enzyme immobilization, including covalent binding, encapsulations, cross-linking, and physical adsorption. ${ }^{11-16}$ Often, immobilization leads to a decrease in enzymatic activity, specificity, and selectivity. However, by choosing the best immobilization method and material for the given application, this attenuation can be reduced or even inverted. ${ }^{17-19}$ Physical adsorption, such as that due to hydrophobicity or van der Waals forces, is often too weak to keep the enzyme fixed to the carrier in industrial conditions such as high stirring or continuous flow. Ionic and covalent binding are generally stronger, which has the advantage that the enzyme cannot be leached from the surface. However, for covalent binding this also has a disadvantage: if the enzyme is irreversibly deactivated while permanently attached to the support, then the support is rendered unusable. Ionic bonding is therefore a suitable medium.

Received: July 29, 2016

Published: August 26, 2016 
Chaperonin-Inspired Enzyme Immobilization. Evolution over millennia has allowed biological systems to create clever solutions to challenges in efficiency and resilience. Drawing inspiration from nature and understanding its fundamental concepts allows for the innovative design of chemical engineering systems. By scientifically identifying the fundamental mechanisms underlying desirable traits and applying these mechanisms to the design and synthesis of artificial systems, one can efficiently borrow the qualities of the natural model.

In this investigation, molecular chaperonins inspire the design of an effective enzyme immobilization material. Chaperonins are proteins that bind unfolded polypeptide chains to help them fold correctly. Chaperonins are essential, as they prevent polypeptide aggregation and precipitation by preventing the improper association of exposed hydrophobic segments. Chaperonins' effectiveness is due to three of their attributes: a narrow, cylindrical pore just large enough to fit a single protein; a local electrostatic environment that encourages rapid protein adsorption; and a hydrophilic core that encourages the correct folding of newly synthesized proteins. $^{20,21}$

The immobilization material chosen for this project is rodlike mesoporous silica SBA-15. SBA-15's pores are block copolymer templated; they are cylindrical and arrayed hexagonally such that they stretch axially down the silica rod. SBA-15's pore diameter is sharply defined and can be controlled within nanometers upon synthesis. ${ }^{22}$ This precise control of pore diameter is particularly useful in our chaperonin-inspired approach, as it allows for the rational design of SBA-15 for a target enzyme size. Further, silica is hydrophilic and negatively charged in most solutions, resulting in a low isoelectric point. These attributes together make it an attractive synthetic analogue to chaperonins and a valuable candidate for enzyme immobilization research. ${ }^{23-25}$

Enzyme immobilization onto porous supports has particular advantages over external surface immobilization. ${ }^{26-29}$ Enzymes on an interior surface will avoid interaction with interfaces, such as those caused by gas bubbles or organic solvent, which can disrupt an enzyme's hydrophobic core. ${ }^{30}$ Previous work on enzyme immobilization onto SBA-15 has indicated that protein adsorption on its internal surface can be adequately described by the Langmuir adsorption model, because the pores are not very much larger than the protein molecules. The Langmuir fit is more accurate when the protein is adsorbed at its isoelectric point. ${ }^{31,32}$ It has also been shown that the maximum amount of adsorbed protein on SBA-15 is influenced more by pore volume than surface area; that is, for sufficiently large pores, enzymes will pack in the available volume in the pores, rather than just adsorb onto the interior surface. ${ }^{33-35}$

A crucial advantage of immobilization on a porous carrier is that it can lead to "rigidification" of the enzyme. ${ }^{19}$ By attaching an enzyme covalently, or, to a lesser extent, ionically, at multiple points to the material's surface, an enzyme's structure is highly stabilized against conformational changes. ${ }^{16,30}$ The effect of adsorption to SBA-15 on the secondary structure of proteins has been investigated using Fourier transform infrared (FTIR) spectroscopy. The secondary structures of the immobilized proteins changed in different ways, with relative percentages of different motifs increasing and decreasing, but both proteins experienced greater departures from their native secondary structures with increasing mesoporous silica pore diameter. ${ }^{36}$ In other words, more tightly confining the proteins resulted in better structural integrity.

The specific aim of this investigation is to help develop mesoporous silica SBA-15 as an enzyme immobilization material. This will be accomplished by investigating the influence of SBA-15's similarities to chaperonins in its ability to protect cargo proteins from denaturation. By probing the effects of pore diameter and surface charge of the SBA-15 materials, we can achieve a better understanding of the fundamentals behind enzyme immobilization in general, and apply this knowledge to the design of new systems.

\section{EXPERIMENTAL SECTION}

Mesoporous Silica SBA-15 Synthesis and Characterization. Rodlike mesoporous silica SBA-15 particles with narrowly controlled pore diameters were synthesized via an acidic sol-gel method. The temperature at which hydrothermal condensation occurs was varied across synthesis batches to produce SBA- 15 with different average pore diameters: batches were aged at 40,75 , or $100{ }^{\circ} \mathrm{C}$. Additional synthetic conditions and procedures can be found in the Supporting Information. $22,37-39$

Nitrogen gas adsorption and desorption isotherms of SBA-15 samples were measured using a Quantachrome Autosorb-iQ automated gas sorption analyzer. Samples were outgassed at $380{ }^{\circ} \mathrm{C}$ for $8 \mathrm{~h}$ before analysis. The samples' specific surface areas were estimated using the standard Brunauer-Emmett-Teller (BET) method, ${ }^{40}$ and the samples' pore size distributions were calculated using non-local density functional theory (NLDFT).$^{41}$

SBA-15 external particle morphologies were observed on a JEOL JSM-6480LV or a Zeiss EVO MA 10 scanning electron microscope (SEM), run in high vacuum mode, typically operating at $7 \mathrm{kV}$, after being spray-coated in gold. SBA-15 pore orientations were observed with a JEOL 2100 transmission electron microscope (TEM) operating at $200 \mathrm{kV}$. Before TEM analysis, samples were dispersed in ethanol and drops of the suspension were added to holey carbon-coated copper TEM grids. Small-angle X-ray scattering (SAXS) patterns were obtained with a Ganesha 300XL instrument by SAXSLAB.

Enzyme Immobilization on Mesoporous Silica SBA-15. Sodium phosphate monobasic $\left(\mathrm{NaH}_{2} \mathrm{PO}_{4}\right)$ (BioXtra, $\left.\geq 99 \%\right)$, sodium phosphate dibasic $\left(\mathrm{Na}_{2} \mathrm{HPO}_{4}\right)$ (BioXtra, $\left.\geq 99 \%\right)$, glacial acetic acid (ACS reagent, $\geq 99.7 \%)$, sodium acetate ( $\geq 99 \%$, anhydrous), myoglobin from equine heart $(\geq 90 \%$, essentially salt-free, lyophilized powder), and lysozyme from chicken egg white (lyophilized powder, protein content $\geq 90 \%, \geq 40,000$ units $/ \mathrm{mg}$ protein) were purchased from Sigma-Aldrich.

To test the protective effects of SBA-15 on immobilized enzyme, myoglobin/SBA-15 and lysozyme/SBA-15 composites were prepared with a target loading of $50 \mathrm{mg}$ of enzyme per gram of SBA-15 in phosphate buffer. First, SBA-15 was suspended in phosphate buffer ( $\mathrm{pH} 7.2, I=0.1)$ at a concentration of $4 \mathrm{~g} / \mathrm{L}$ and sonicated to ensure that it was well dispersed. Enzyme solutions were prepared in the same buffer at $0.2 \mathrm{~g} / \mathrm{L}$. The SBA-15 solution was then mixed with an equal volume of enzyme solution for a final SBA-15 concentration of $2 \mathrm{~g} / \mathrm{L}$ and enzyme concentration of $0.1 \mathrm{~g} / \mathrm{L}$. This composite solution was agitated overnight at room temperature to ensure equilibrium.

After the enzyme had adsorbed to the SBA-15 over $24 \mathrm{~h}$, the solutions were centrifuged at $12000 \mathrm{rpm}$ for $5 \mathrm{~min}$, and the supernatant and pelleted SBA-15 were separated. The concentration of enzyme in the supernatant was measured via ultraviolet-visible (UVvis) spectrophotometry at a characteristic absorbance wavelength of $280 \mathrm{~nm}$ (and also $409 \mathrm{~nm}$ for myoglobin). UV-vis spectroscopy was carried out using the absorbance mode of a BioTek Synergy H1MultiDetection Reader. These measurements were compared to a calibration curve, and the enzyme concentrations were determined by the Beer-Lambert law. The amount of enzyme adsorbed to the SBA-15 was calculated using a mass balance. ${ }^{33}$

Exposure of Immobilized Enzymes to Unfavorable pH. Next, myoglobin/SBA-15 and lysozyme/SBA-15 composites were prepared 
and exposed to a range of $\mathrm{pH}$ conditions. The enzyme/SBA-15 composites were resuspended to $2 \mathrm{~g} / \mathrm{L}$ in either acetate or phosphate buffers of varying $\mathrm{pH}$, but all of $I=0.1$. Acetate buffers were prepared by mixing a $100 \mathrm{mM}$ solution of acetic acid and a $100 \mathrm{mM}$ solution of sodium acetate to make buffers with final $\mathrm{pH}$ values of 3.6, 4.1, 4.6, 5.1, and 5.6. Phosphate buffers were prepared by mixing a $100 \mathrm{mM}$ solution of sodium phosphate monobasic and a $33.3 \mathrm{mM}$ solution of sodium phosphate dibasic to make buffers with final $\mathrm{pH}$ values of 5.6, 6.1, 6.6, and 7.6. All of these buffer solutions necessarily have $I=0.1$.

After the enzyme/SBA-15 composites were agitated for $24 \mathrm{~h}$ at room temperature in their test buffers, they were centrifuged again. The supernatant was saved and measured with UV-vis to determine enzyme leaching. The pellets were resuspended in the same buffers (of varying $\mathrm{pH}$ values), and their enzymatic activity was immediately quantified. Each combination of pore size, $\mathrm{pH}$, and enzyme was prepared in triplicate. Myoglobin containing samples were additionally measured in triplicate.

These experimental conditions were replicated for $0.1 \mathrm{~g} / \mathrm{L}$ solutions of free myoglobin or lysozyme in the same series of buffers, as controls. In these experiments, lyophilized enzyme was suspended directly into the acetate or phosphate buffers of varying $\mathrm{pH}$ values, and agitated for $24 \mathrm{~h}$ at room temperature. Then, each solution's enzymatic activity was quantified.

For myoglobin-containing samples, enzymatic activity was quantified using a colorimetric, peroxidase assay indicated with 2,2'-azinobis(3-ethylbenzothiazoline-6-sulfonic acid) (ABTS). For lysozymecontaining samples, activity was quantified using a fluorometric, glycanase assay indicated with 4-methylumbelliferyl $\beta$-D- $N, N^{\prime}, N^{\prime}$ triacetylchitotrioside. Both assays were monitored with a BioTek Synergy H1Multi-Detection Reader. More information on these assays can be found in the Supporting Information.

To confirm the SBA-15 samples' colloidal stability in the aforementioned acetate or phosphate buffers, separately prepared 2 $\mathrm{g} / \mathrm{L}$ samples of each batch of SBA-15 in each buffer were measured with dynamic light scattering (DLS) with a Brookhaven NanoBrook Omni particle sizer to determine their particle size and check for aggregation. The sample solutions were sonicated prior to measurement. No aggregation was observed in any buffer for any sample, as the average hydrodynamic diameter of the particles agreed with the particle dimensions observed in SEM.

\section{RESULTS AND DISCUSSION}

Mesoporous Silica SBA-15 Characterization. For porous materials, nitrogen physisorption can be used to determine the shape, size, and volume of the pores, and the material's total surface area. Nitrogen adsorption and desorption isotherms of all SBA-15 samples contain hysteresis loops defined as type $\mathrm{H} 1$ by the IUPAC classification, which is associated with well-defined cylindrical pore channels. ${ }^{42}$ These adsorption and desorption isotherms can be found in the Supporting Information.

The narrow pore size distributions shown in Figure 1, calculated by the NLDFT method, indicate good control of the SBA-15's mesopore diameter. As found in other studies, pore size increases at higher hydrothermal aging temperatures. ${ }^{37}$

Table 1 shows the morphological parameters derived from nitrogen physisorption of all SBA-15 samples. Total surface area, calculated by the BET method, increases with increasing synthesis temperature for all SBA-15 batches. The volume of pores smaller than $50 \mathrm{~nm}$ also increases with increasing synthesis temperature for all samples. These pore volume values include micropores ( $<2 \mathrm{~nm}$ in diameter) and mesopores (2-50 $\mathrm{nm}$ in diameter). No appreciable macropore volume is observed for any sample.

SEM is used to determine the external morphology and particle dimensions for the synthesized SBA-15 materials. SEM shows that all SBA-15 particles have a rodlike morphology and

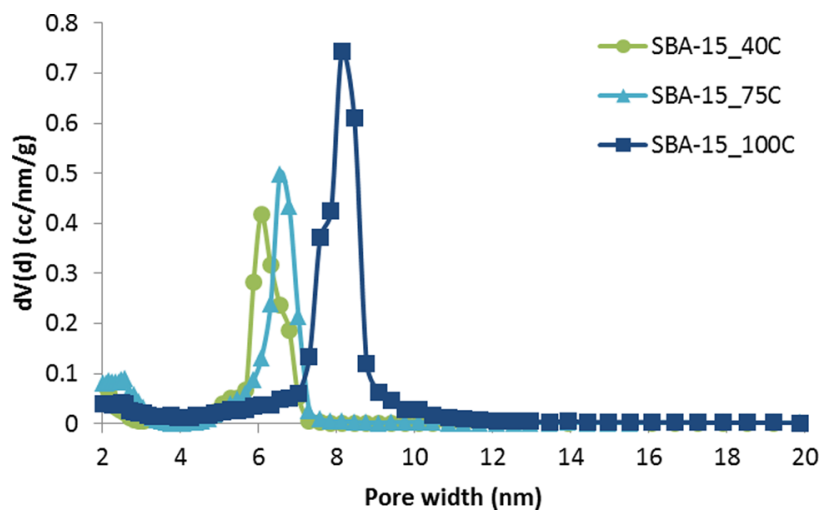

Figure 1. NLDFT pore size distributions of mesoporous silica SBA-15, synthesized at 40,75 , and $100{ }^{\circ} \mathrm{C}$, derived from $\mathrm{N}_{2}$ adsorption.

Table 1. Textural Parameters Derived from N2 Adsorption of Mesoporous Silica SBA-15 Particles Synthesized at 40, 75, and $100{ }^{\circ} \mathrm{C}$

\begin{tabular}{cccc}
$\begin{array}{c}\text { synthesis } \\
\text { temperature } \\
\left({ }^{\circ} \mathrm{C}\right)\end{array}$ & $\begin{array}{c}\text { NLDFT pore } \\
\text { diameter }(\mathrm{nm})\end{array}$ & $\begin{array}{c}\text { BET surface } \\
\text { area }\left(\mathrm{m}^{2} / \mathrm{g}\right)\end{array}$ & $\begin{array}{c}\text { micro- and mesopore } \\
\text { volume }\left(\mathrm{cm}^{3} / \mathrm{g}\right)\end{array}$ \\
40 & 6.1 & 505 & 0.491 \\
75 & 6.6 & 602 & 0.656 \\
100 & 8.1 & 685 & 1.093 \\
\hline
\end{tabular}

that their particle size distributions have low polydispersity. A single SBA- 15 particle is approximately $1 \mu \mathrm{m}$ in length. From these micrographs, it appears that the hydrothermal aging temperature affects the particles thickness: SBA-15_40C particles have an approximate diameter of $400 \mathrm{~nm}$, while SBA-15_100C particles have an approximate diameter of 300 $\mathrm{nm}$. SEM micrographs can be found in the Supporting Information.

TEM is used to observe the internal morphology of the synthesized SBA-15 particles and shows the orientation and shape of their internal pores. Pores are found to be oriented down the length of the rodlike particles, and very low tortuosity of the pores is observed. TEM micrographs can be found in the Supporting Information.

SAXS patterns of the three conventionally synthesized SBA15 materials show that all three samples have an ordered pore structure. SBA-15 is known to have hexagonally ordered, cylindrical parallel pores, corresponding to the $p 6 \mathrm{~mm}$ space group. The Miller indices of the three peaks found in SBA-15 SAXS spectra are then (100), (110), and (200). ${ }^{32}$ Unit cell dimensions can be calculated from these peaks. The pore wall thicknesses for all SBA-15 batches are very similar. SAXS spectra and derived data can be found in the Supporting Information.

Acidic Protection of Immobilized Myoglobin. Myoglobin immobilized on SBA-15 of different pore diameters is exposed to a range of $\mathrm{pH}$ conditions, and then its peroxidase activity is measured by assay at that $\mathrm{pH}$. This is done to examine the relationship between $\mathrm{pH}$ and immobilized enzyme activity, and probe for possible protective effects of SBA- 15 on the immobilized enzymes from denaturing acidic and alkaline conditions. Myoglobin loading onto SBA-15 is targeted for 50 mg per gram of SBA-15.

Figure 2a shows the peroxidase activity of free myoglobin, as well as of myoglobin immobilized on SBA-15 of different pore diameters. The activity is shown in arbitrary units, proportional 

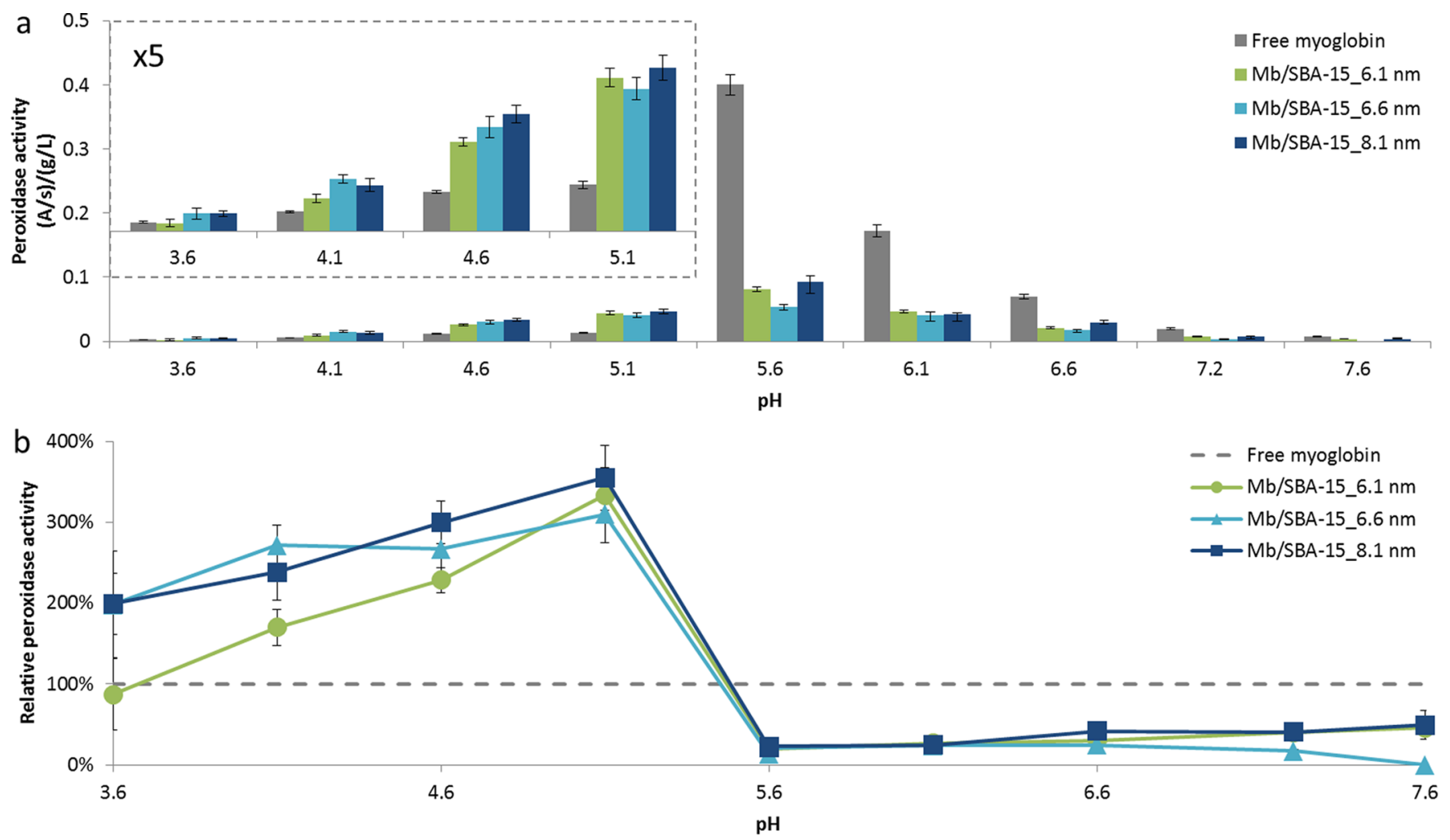

Figure 2. (a) Peroxidase activities of free myoglobin and myoglobin immobilized to mesoporous silica SBA-15, with pore diameters of 6.1, 6.6, and $8.1 \mathrm{~nm}$, in solutions of varying $\mathrm{pH}(3.6$ to 7.6$)$ at ionic strength 0.1 . (b) Relative peroxidase activity of the same samples. Error bars depict $95 \%$ confidence intervals.
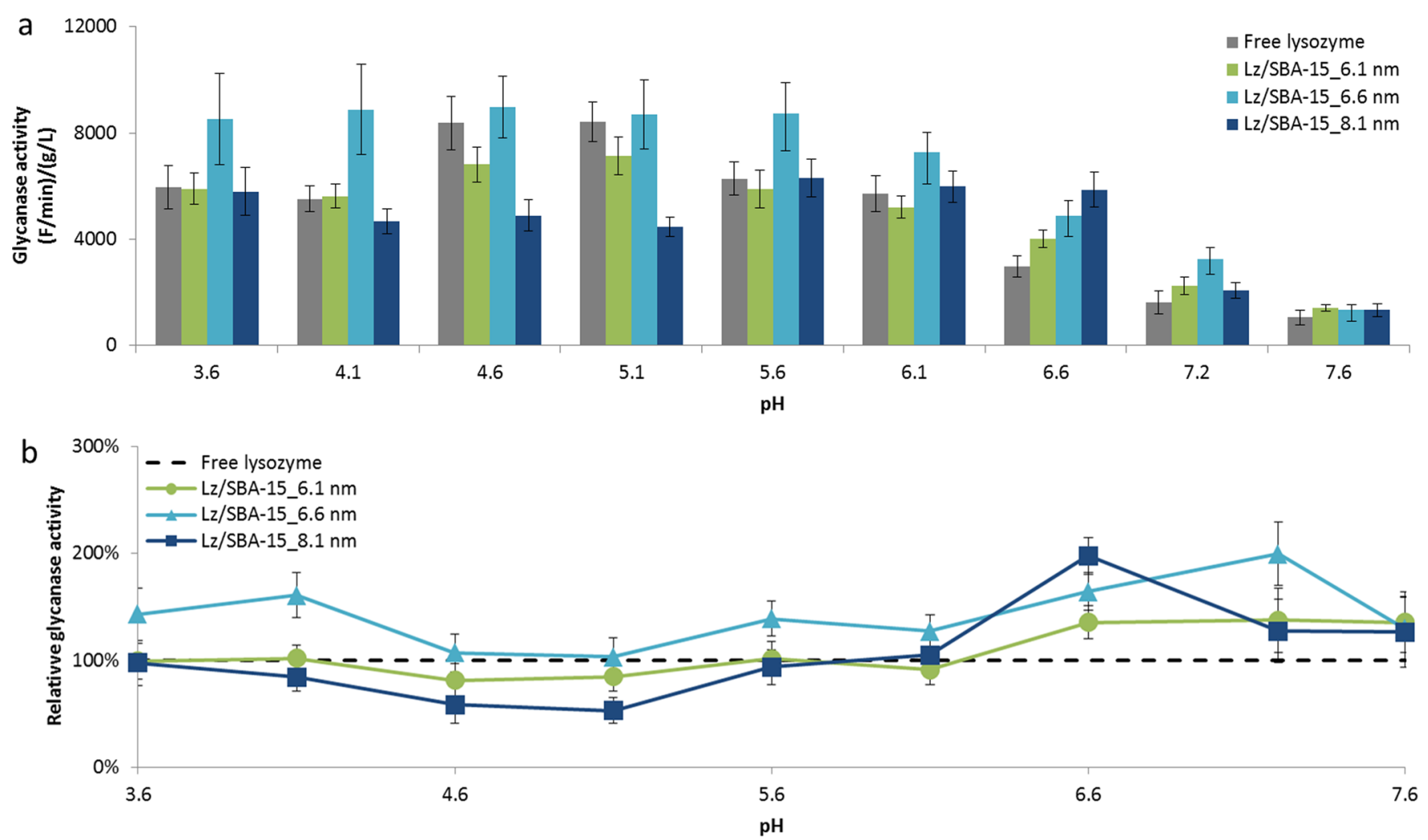

Figure 3. (a) Glycanase activities of free lysozyme and lysozyme immobilized on mesoporous silica SBA-15, with pore diameters of 6.1, 6.6, and 8.1 $\mathrm{nm}$, in solutions of varying $\mathrm{pH}$ (3.6 to 7.6) at ionic strength 0.1. (b) Relative glycanase activity of the same samples. Error bars depict $95 \%$ confidence intervals. 
to the rate of the peroxidase reaction (absorbance per second) and divided by the concentration of myoglobin in the sample $(\mathrm{g} / \mathrm{L})$. At $\mathrm{pH} 5.6$, samples are prepared in both phosphate and acetate buffers, at the same ionic strength, and the samples' activities are found to be within error of each other. This alone is a useful finding, as it suggests that the buffer salt used does not have a significant effect on the enzyme's activity.

Myoglobin acts as a peroxidase on the ABTS substrate most effectively between $\mathrm{pH} 5.1$ and 5.6, as can be seen by the free myoglobin bars in Figure 2a. This optimal activity decreases slowly at more alkaline $\mathrm{pH}$ values, but rapidly at more acidic $\mathrm{pH}$ values. The quick decrease in activity may be attributed to the denaturation of myoglobin in acidic conditions. From this graph we can see that myoglobin immobilized on SBA-15 performs significantly worse than myoglobin free in aqueous solution and at its optimal $\mathrm{pH}$.

Figure $2 \mathrm{~b}$ depicts the same data, shown normalized to the activity of the free myoglobin at each $\mathrm{pH}$. The activity of confined myoglobin surpasses that of free myoglobin at low $\mathrm{pH}$ values, up to $350 \%$. This indicates that confined myoglobin is protected, to some extent, from denaturing due to the acidic environment. Immobilized myoglobin does not enjoy this protective effect at $\mathrm{pH}$ values greater than 5.1.

Focusing solely on the acidic $\mathrm{pH}$ range where immobilized myoglobin's activity exceeds that of free myoglobin, we can see in the inset of Figure $2 \mathrm{~b}$ that the protective effect appears to diminish as the $\mathrm{pH}$ decreases. We can also see that, for this set of experiments, $\mathrm{pH}$ protection does not appear to be affected significantly by the SBA-15's pore size. Immobilization onto SBA-15 does not improve myoglobin's peroxidase activity at all $\mathrm{pH}$ values tested. However, confinement to SBA-15 does shift the effective activity range of myoglobin to more acidic $\mathrm{pH}$ values with dramatic protection up to $350 \%$.

Some myoglobin leaching is observed during the $\mathrm{pH}$ exposure step; these data can be found in the Supporting Information. Leaching is accounted for in the activity measurements. Myoglobin leaching remains under 15\% for almost all SBA-15 samples in most batches. More leaching is observed from all SBA-15 at the higher $\mathrm{pH}$ values of 7.2 and 7.6. This is to be expected, as myoglobin will have a net neutral charge near these $\mathrm{pH}$ values and not be as strongly attracted to the negatively charged silica surface. These data are also helpful in confirming that the different SBA-15 batches have similar surface charge profiles. If the materials had very different surface charges, then the amount of myoglobin leached at different $\mathrm{pH}$ values should also be different because the leaching is shown to be very dependent on the extent of electrostatic attraction between the protein and the material surface. Since the amount of myoglobin leached at each $\mathrm{pH}$ is within error between the different SBA-15 batches, the materials' surface charge at each $\mathrm{pH}$ must be very similar.

Alkaline Protection of Immobilized Lysozyme. To further investigate the relationship between $\mathrm{pH}$ and immobilized enzyme activity, and probe for possible protective effects of SBA-15, lysozyme is also immobilized on SBA-15 of different pore diameters and exposed to a range of $\mathrm{pH}$ conditions. Then, their glycanase activity is measured by an assay at that $\mathrm{pH}$. As with myoglobin, lysozyme loading onto SBA-15 is targeted for $50 \mathrm{mg}$ per gram of SBA-15.

Figure 3a shows the glycanase activity of free lysozyme, as well as of lysozyme immobilized on SBA-15 of different pore diameters. The activity is shown in arbitrary units proportional to the speed of the glycanase reaction (fluorescence, F, per minute) divided by the concentration of lysozyme in the sample $(\mathrm{g} / \mathrm{L})$. Small amounts of lysozyme leaching are observed while the samples are left in the test buffer for 24 h. Leaching is always accounted for in specific activity calculations. At $\mathrm{pH}$ 5.6, both phosphate and acetate buffers are used at the same ionic strength. In these buffers, the sample's activities are found to be within error of each other. Again, this is useful as it suggests that the buffer salt used does not have a significant effect on lysozyme's activity.

Lysozyme acts as a glycanase on the fluorogenic substrate most effectively between $\mathrm{pH} 4.6$ and 5.1, as can be seen by the free lysozyme bars in Figure 3a. This optimal activity drops off more slowly at lower and higher $\mathrm{pH}$ values than that of myoglobin; this makes sense, because myoglobin has evolved to operate in a very specific $\mathrm{pH}$ environment inside of muscle tissue ( $\mathrm{pH} 7.2$ ), whereas lysozyme must remain functional within the larger range of $\mathrm{pH}$ values found in egg whites $(\mathrm{pH}$ 7.6 to 9.8 ).

Figure $3 \mathrm{~b}$ depicts the same data, shown normalized to the activity of the free lysozyme at each $\mathrm{pH}$. The activity of confined lysozyme surpasses that of free lysozyme at $\mathrm{pH}$ values that are more alkaline than the optimal $\mathrm{pH}$, up to $200 \%$. This implies that confined lysozyme is protected to some extent. Protective effects are not clearly evident at $\mathrm{pH}$ values below 6.6. However, lysozyme immobilized on SBA-15_6.6 nm always performs at least as well as, if not better than, free lysozyme. SBA-15_6.6 nm also shows protective effects against more acidic conditions at $\mathrm{pH} 3.6$ and 4.1. This is a unique result, and may indicate that this particular pore diameter is especially suited to stabilize and improve the glycanase activity of lysozyme for reasons that are not yet fully understood.

Focusing specifically on the $\mathrm{pH}$ range where SBA-15 demonstrates some protective effects on lysozyme, on the more alkaline side of the assay's optimal $\mathrm{pH}$, we see that, in many cases, the activities of lysozyme immobilized on SBA$15 \_5.7 \mathrm{~nm}$ and SBA-15_8.1 nm are within error of that of free lysozyme. This is a modest but positive result, as at least immobilization does not hinder the enzyme's activity and it can still be more easily reused.

The pore size of the SBA-15 does appear to play a role in the extent to which lysozyme's activity is modified. Particularly at $\mathrm{pH} 6.6$, we can see a clear trend of larger pore sizes leading to a greater increase in activity. Immobilization onto SBA-15 does not improve lysozyme's glycanase activity at all $\mathrm{pH}$ values tested. However, confinement to SBA-15 does widen lysozyme's effective activity range, with substantial alkaline protection up to $200 \%$.

Some lysozyme leaching is observed while the samples are left in the test buffer for $24 \mathrm{~h}$, which is accounted for in specific activity calculations. These data can be found in the Supporting Information. Lysozyme leaching exceeds that of myoglobin at some $\mathrm{pH}$ values, leaching up to $60 \%$ at the low $\mathrm{pH}$ of 3.6. At low $\mathrm{pH}$ values, lysozyme will be very strongly positively charged, while the silica surface will be weakly negative. The increased leaching may be caused by the lysozyme-lysozyme repulsion superseding the lysozyme-silica attraction. As with the myoglobin leaching data, these data are also helpful in confirming that the different SBA-15 batches have similar surface charge profiles.

Electrostatics Drives pH Protection. The results of this study give insight into which aspects of the immobilization material are most important for predicting and tuning protective effects. 
Mesoporous silica's isoelectric point is typically found around $\mathrm{pH}$ 2. Myoglobin's isoelectric point is 7.2. In any solution between $\mathrm{pH} 2$ and 7.2, mesoporous silica has a negative net surface charge and myoglobin has a positive net surface charge, and the myoglobin molecules are electrostatically attracted to the silica surface. This attraction will be strongest at the center of this $\mathrm{pH}$ range. We found that myoglobin immobilized to SBA-15 demonstrated the highest activity, or the strongest protective effects, at $\mathrm{pH}$ 5.1. As seen in Scheme 1, this corresponds directly to the $\mathrm{pH}$ value at which myoglobin and mesoporous silica experience the strongest electrostatic attraction.

Scheme 1. Electrostatic Attraction of Silica $(\mathrm{pI} \sim 2)$ and Myoglobin ( $\mathrm{pI}=7.2)$ to Each Other in Solutions with $\mathrm{pH}$ between 2 and $7.2^{a}$

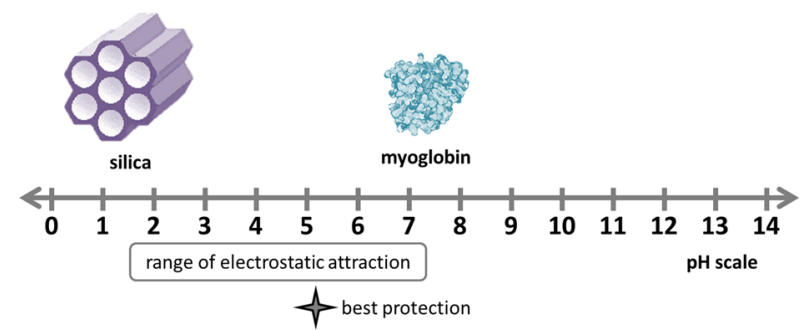

${ }^{a}$ In these solutions, silica is negatively charged and myoglobin is positively charged. Immobilization to SBA-15 is found to have the most beneficial effect on myoglobin's peroxidase activity at $\mathrm{pH}$ 5.1, which is a $\mathrm{pH}$ value at which silica and myoglobin are strongly attracted to each other.

A similar argument can be made for lysozyme, whose isoelectric point is 11.3. Therefore, in any aqueous solution between $\mathrm{pH} 2$ and 11.3, mesoporous silica has a negative net surface charge and lysozyme has a positive net surface charge, so that lysozyme molecules are electrostatically attracted to the silica surface. Our experiments showed that lysozyme immobilized to SBA-15 demonstrated the highest relative activity, corresponding to the strongest protective effects, at $\mathrm{pH}$ 6.6, as seen in Scheme 2. Again, this correlates directly to the $\mathrm{pH}$ value at which lysozyme and mesoporous silica experience the strongest electrostatic attraction. Together these two sets of results indicate that electrostatic attraction drives the increased enzymatic activity observed when immobilizing either enzyme

Scheme 2. Electrostatic Attraction of Silica $(\mathrm{pI} \sim 2)$ and Lysozyme ( $\mathrm{pI}=11.3)$ to Each Other in Solutions with $\mathrm{pH}$ between 2 and $11.3^{a}$

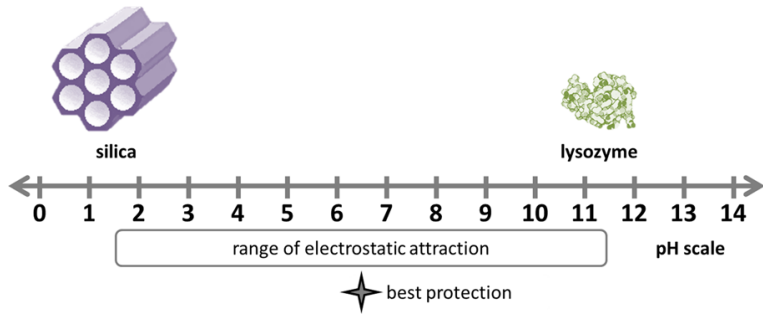

${ }^{a}$ In these solutions, silica is negatively charged and lysozyme is positively charged. Immobilization to SBA-15 is found to have the most beneficial effect on lysozyme's glycanase activity at $\mathrm{pH}$ 6.6, which is the $\mathrm{pH}$ value at which silica and lysozyme are the most strongly attracted to each other. with the physical adsorption method, a result that is likely to be more general.

\section{SUMMARY AND CONCLUSIONS}

This paper discussed $\mathrm{pH}$ protection of enzymes by immobilization on the pore surface of mesoporous silica with controlled pore diameters slightly larger than the size of the enzymes. Batches of ordered mesoporous silica SBA-15 with different, unique pore diameters were synthesized by a templated sol-gel method. The materials were characterized using $\mathrm{N}_{2}$ gas adsorption, SEM, TEM, SAXS, and DLS.

Immobilizing two common enzymes, lysozyme and myoglobin, to SBA-15 was shown to increase their biocatalytic activity under some solution conditions, compared to the activity of the same enzyme free in the same solution. For myoglobin, these protective effects were observed on the acidic side of the $\mathrm{pH}$ range tested ( $\mathrm{pH} 3.6$ to 5.6). For lysozyme, the protective effects were seen on the alkaline side of the $\mathrm{pH}$ range tested ( $\mathrm{pH} 5.1$ to 7.6 ). For both enzymes, the protective effects were strongest for $\mathrm{pH}$ values where the enzyme is strongly electrostatically attracted to the silica surface. The different buffer salts used, acetate and phosphate, were not found to significantly affect enzyme leaching or activity. Pore size may affect SBA-15 pH protective effects, as seen with lysozyme, but further work is required to validate this.

\section{ASSOCIATED CONTENT}

\section{S Supporting Information}

The Supporting Information is available free of charge on the ACS Publications website at DOI: 10.1021/acs.langmuir.6b02832.

SBA-15 synthesis method; electron micrographs, $\mathrm{N}_{2}$ sorption isotherms, and SAXS scattering patterns of synthesized SBA-15; peroxidase and glycanase assays for determining myoglobin and lysozyme enzymatic activity, respectively; and leaching profiles of immobilized myoglobin and lysozyme (PDF)

\section{AUTHOR INFORMATION}

\section{Corresponding Author}

*E-mail: m.coppens@ucl.ac.uk.

\section{Notes}

The authors declare no competing financial interest.

\section{ACKNOWLEDGMENTS}

The research leading to these results has received funding from an EPSRC Frontier Engineering Award (EP/K038656/1).

\section{REFERENCES}

(1) Panke, S.; Held, M.; Wubbolts, M. Trends and Innovations in Industrial Biocatalysis for the Production of Fine Chemicals. Curr. Opin. Biotechnol. 2004, 15 (4), 272-279.

(2) Straathof, A. J. J.; Panke, S.; Schmid, A. The Production of Fine Chemicals by Biotransformations. Curr. Opin. Biotechnol. 2002, 13, 548-556.

(3) Nestl, B. M.; Hammer, S. C.; Nebel, B. a; Hauer, B. New Generation of Biocatalysts for Organic Synthesis. Angew. Chem., Int. Ed. 2014, 53 (12), 3070-3095.

(4) Panke, S.; Wubbolts, M. Advances in Biocatalytic Synthesis of Pharmaceutical Intermediates. Curr. Opin. Chem. Biol. 2005, 9 (2), 188-194. 
(5) Huisman, G. W.; Collier, S. J. On the Development of New Biocatalytic Processes for Practical Pharmaceutical Synthesis. Curr. Opin. Chem. Biol. 2013, 17 (2), 284-292.

(6) Patel, R. N. Synthesis of Chiral Pharmaceutical Intermediates by Biocatalysis. Coord. Chem. Rev. 2008, 252 (5-7), 659-701.

(7) Pollard, D. J.; Woodley, J. M. Biocatalysis for Pharmaceutical Intermediates: The Future Is Now. Trends Biotechnol. 2007, 25 (2), 66-73.

(8) Woodley, J. M. New Opportunities for Biocatalysis: Making Pharmaceutical Processes Greener. Trends Biotechnol. 2008, 26 (6), 321-327.

(9) Tao, J.; Xu, J.-H. Biocatalysis in Development of Green Pharmaceutical Processes. Curr. Opin. Chem. Biol. 2009, 13 (1), 4350 .

(10) Wohlgemuth, R. Biocatalysis-Key to Sustainable Industrial Chemistry. Curr. Opin. Biotechnol. 2010, 21 (6), 713-724.

(11) Tran, D. N.; Balkus, K. J. Perspective of Recent Progress in Immobilization of Enzymes. ACS Catal. 2011, 1 (8), 956-968.

(12) Sheldon, R. A. Enzyme Immobilization: The Quest for Optimum Performance. Adv. Synth. Catal. 2007, 349 (8-9), 12891307.

(13) Sheldon, R. a; van Pelt, S. Enzyme Immobilisation in Biocatalysis: Why, What and How. Chem. Soc. Rev. 2013, 42 (15), 6223-6235.

(14) Hanefeld, U.; Gardossi, L.; Magner, E. Understanding Enzyme Immobilisation. Chem. Soc. Rev. 2009, 38 (2), 453-468.

(15) Hanefeld, U.; Cao, L.; Magner, E. Enzyme Immobilisation: Fundamentals and Application. Chem. Soc. Rev. 2013, 42 (15), 62116212.

(16) Garcia-Galan, C.; Berenguer-Murcia, Á.; Fernandez-Lafuente, R.; Rodrigues, R. C. Potential of Different Enzyme Immobilization Strategies to Improve Enzyme Performance. Adv. Synth. Catal. 2011, 353 (16), 2885-2904.

(17) Cao, L. Immobilised Enzymes: Science or Art? Curr. Opin. Chem. Biol. 2005, 9, 217-226.

(18) Cao, L.; Langen, L. v.; Sheldon, R. a. Immobilised Enzymes: Carrier-Bound or Carrier-Free? Curr. Opin. Biotechnol. 2003, 14, 387394.

(19) Rodrigues, R. C.; Ortiz, C.; Berenguer-Murcia, Á.; Torres, R.; Fernández-Lafuente, R. Modifying Enzyme Activity and Selectivity by Immobilization. Chem. Soc. Rev. 2013, 42 (15), 6290-6307.

(20) Braig, K.; Otwinowski, Z.; Hegde, R.; Boisvert, D. C.; Joachimiak, A.; Horwich, A. L.; Sigler, P. B. The Crystal Structure of the Bacterial Chaperonin GroEL at 2.8 A. Nature 1994, 371, 578-586.

(21) Tartaglia, G. G.; Dobson, C. M.; Hartl, F. U.; Vendruscolo, M. Physicochemical Determinants of Chaperone Requirements. J. Mol. Biol. 2010, 400 (3), 579-588.

(22) Zhao, D.; Feng, J.; Huo, Q.; Melosh, N.; Fredrickson, G.; Chmelka, B.; Stucky, G. Triblock Copolymer Syntheses of Mesoporous Silica with Periodic 50 to 300 Angstrom Pores. Science (Washington, DC, U. S.) 1998, 279, 548-552.

(23) Hudson, S.; Magner, E.; Cooney, J.; Hodnett, B. K. Methodology for the Immobilization of Enzymes onto Mesoporous Materials. J. Phys. Chem. B 2005, 109 (41), 19496-19506.

(24) Essa, H.; Magner, E.; Cooney, J.; Hodnett, B. K. Influence of pH and Ionic Strength on the Adsorption, Leaching and Activity of Myoglobin Immobilized onto Ordered Mesoporous Silicates. J. Mol. Catal. B: Enzym. 2007, 49 (1-4), 61-68.

(25) Ikemoto, H.; Chi, Q.; Ulstrup, J. Stability and Catalytic Kinetics of Horseradish Peroxidase Confined in Nanoporous SBA-15. J. Phys. Chem. C 2010, 114 (39), 16174-16180.

(26) Hartmann, M. Ordered Mesoporous Materials for Bioadsorption and Biocatalysis. Chem. Mater. 2005, 17, 4577-4593.

(27) Zhou, Z.; Hartmann, M. Progress in Enzyme Immobilization in Ordered Mesoporous Materials and Related Applications. Chem. Soc. Rev. 2013, 42 (9), 3894-3912.

(28) Hartmann, M.; Kostrov, X. Immobilization of Enzymes on Porous Silicas-Benefits and Challenges. Chem. Soc. Rev. 2013, 42 (15), 6277-6289.
(29) Hudson, S.; Cooney, J.; Magner, E. Proteins in Mesoporous Silicates. Angew. Chem., Int. Ed. 2008, 47 (45), 8582-8594.

(30) Mateo, C.; Palomo, J. M.; Fernandez-Lorente, G.; Guisan, J. M.; Fernandez-Lafuente, R. Improvement of Enzyme Activity, Stability and Selectivity via Immobilization Techniques. Enzyme Microb. Technol. 2007, 40 (6), 1451-1463.

(31) Vinu, A.; Murugesan, V.; Tangermann, O.; Hartmann, M. Adsorption of Cytochrome $\mathrm{c}$ on Mesoporous Molecular Sieves: Influence of $\mathrm{pH}$, Pore Diameter, and Aluminum Incorporation. Chem. Mater. 2004, 16, 3056-3065.

(32) Katiyar, A.; Ji, L.; Smirniotis, P.; Pinto, N. G. Protein Adsorption on the Mesoporous Molecular Sieve Silicate SBA-15: Effects of $\mathrm{pH}$ and Pore Size. J. Chromatogr. A 2005, 1069 (1), 119-126.

(33) Sang, L.-C.; Vinu, A.; Coppens, M.-O. General Description of the Adsorption of Proteins at Their Iso-Electric Point in Nanoporous Materials. Langmuir 2011, 27 (22), 13828-13837.

(34) Carlsson, N.; Gustafsson, H.; Thörn, C.; Olsson, L.; Holmberg, K.; Åkerman, B. Enzymes Immobilized in Mesoporous Silica: A Physical-Chemical Perspective. Adv. Colloid Interface Sci. 2014, 205, 339-360.

(35) Vinu, A.; Murugesan, V.; Hartmann, M. Adsorption of Lysozyme over Mesoporous Molecular Sieves MCM-41 and SBA-15: Influence of $\mathrm{pH}$ and Aluminum Incorporation. J. Phys. Chem. B 2004, 108 (22), 7323-7330.

(36) Sang, L.-C.; Coppens, M.-O. Effects of Surface Curvature and Surface Chemistry on the Structure and Activity of Proteins Adsorbed in Nanopores. Phys. Chem. Chem. Phys. 2011, 13 (14), 6689-6698.

(37) Sayari, A.; Han, B.-H.; Yang, Y. Simple Synthesis Route to Monodispersed SBA-15 Silica Rods. J. Am. Chem. Soc. 2004, 126 (44), $14348-14349$.

(38) Galarneau, A.; Cambon, H.; Di Renzo, F.; Fajula, F. True Microporosity and Surface Area of Mesoporous SBA-15 Silicas as a Function of Synthesis Temperature. Langmuir 2001, 17 (26), 83288335.

(39) Kruk, M.; Jaroniec, M.; Ko, C. H.; Ryoo, R. Characterization of the Porous Structure of SBA-15. Chem. Mater. 2000, 12 (7), 19611968.

(40) Brunauer, S.; Emmett, P.; Teller, E. Adsorption of Gases in Multimolecular Layers. J. Am. Chem. Soc. 1938, 60 (1), 309.

(41) Ravikovitch, P. I.; Neimark, A. V. Characterization of Micro- and Mesoporosity in SBA-15 Materials from Adsorption Data by the NLDFT Method. J. Phys. Chem. B 2001, 105 (29), 6817-6823.

(42) Thommes, M.; Kaneko, K.; Neimark, A. V.; Olivier, J. P.; Rodriguez-Reinoso, F.; Rouquerol, J.; Sing, K. S. W. Physisorption of Gases, with Special Reference to the Evaluation of Surface Area and Pore Size Distribution (IUPAC Technical Report). Pure Appl. Chem. 2015, 87 (9-10), 1051-1069. 